
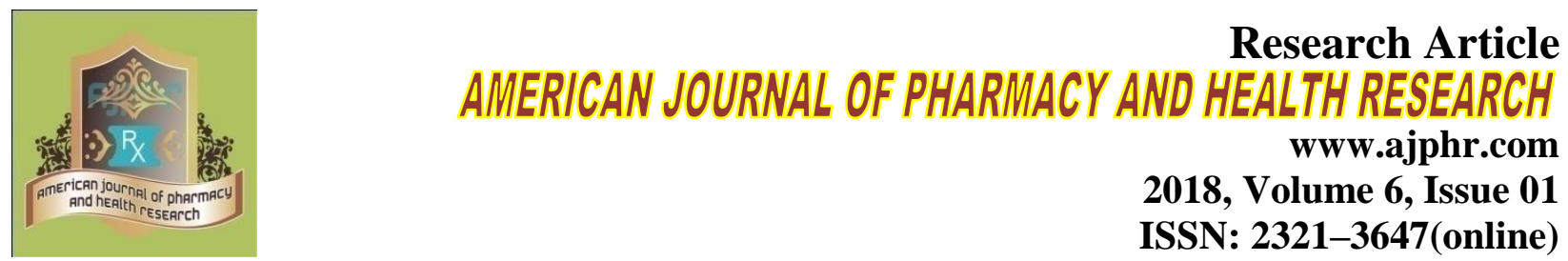

2018, Volume 6, Issue 01

ISSN: 2321-3647(online)

\title{
Study on Neutrophil - Lymphocyte ratio among women with Gestational diabetes mellitus
}

\author{
P.L.Rajagopal ${ }^{1}$, K.R.Sreejith ${ }^{1}$, K.Premaletha ${ }^{1}$, S.Aneeshia ${ }^{2}$ \\ 1. Department of Pharmacognosy and Phytochemistry, Academy of Pharmaceutical Sciences, \\ Pariyaram Medical College, Kannur, Kerala. \\ 2.Department of Medical Laboratory Technology, Academy of Paramedical Sciences, Pariyaram \\ Medical College, Kannur, Kerala.
}

\begin{abstract}
The aim of the present study was to evaluate the neutrophil lymphocyte ratio as a predictive marker of gestational diabetes. Total leukocyte counts and differential leukocyte counts were measured manually. The results after analysis revealed that there was an increased neutrophil lymphocyte ratio among the women with gestational diabetes mellitus.

Keywords: Neutrophil, lymphocyte, Gestational Diabetes Mellitus
\end{abstract}




\section{INTRODUCTION}

Gestational diabetes is one of the most common health problems for pregnant women. It affects about 5 percent 1 of all pregnancies, which means there are about 200,000 cases each year. If not treated, gestational diabetes can cause health problems for mother and foetus. The good news is that gestational diabetes can be treated, especially if it's found early in the pregnancy. There are some things that women with gestational diabetes can do to keep themselves well and their pregnancies healthy. Controlling gestational diabetes is the key to a healthy pregnancy. If not treated, gestational diabetes can lead to health problems, some of them are serious. The best way to promote a healthy pregnancy if we have gestational diabetes is to follow the treatment plan outlined by the health care provider ${ }^{1}$.

\section{Gestational diabetes}

It can be defined as "carbohydrate intolerance of variable severity with onset or first recognition during pregnancy"2. Women diagnosed to have GDM are at increased risk of future diabetes predominantly type II diabetes mellitus (DM) as are their children. Thus, GDM offers an important opportunity for the development, testing and implementation of clinical strategies for diabetes prevention ${ }^{3}$. Approximately $7 \%$ of all pregnancies are complicated by GDM, resulting in more than 200,000 cases annually. The prevalence may range from 1 to $14 \%$ of all pregnancies, depending on the population studied and the diagnostic test employed ${ }^{4}$. Most women who have gestational diabetes give birth to healthy babies, especially when they keep their blood sugar under control, eat a healthy diet, get regular, moderate physical activity, and remain a healthy weight. In some cases, though, the condition can affect the pregnancy.

\section{Neutrophils}

These are the predominant immune cell population in human blood, where they patrol and protect us from pathogens, and diseases with neutropenia show that they are indispensable for controlling bacterial and fungal infections. Neutrophils develop in the bone marrow from haematopoietic stem cells in a process called granulopoiesis ${ }^{5}$. Neutrophils, the most abundant human immune cells, are rapidly recruited to sites of infection, where they fulfil their life-saving antimicrobial functions. While traditionally regarded as short-lived phagocytes. Neutrophils are sexually dimorphic. Neutrophils from women exhibit a small additional x chromosome structure, known as a "neutrophil drumstick". Neutrophil show increased segmentation as they mature. A normal neutrophil should have 3- 5 segments ${ }^{6}$.

\section{Lymphocyte}


These are small white blood cell (leukocyte) that plays a large role in defending the body against disease. Lymphocytes are responsible for immune responses. There are two main types of lymphocytes: $\mathrm{B}$ cells and $\mathrm{T}$ cells. The $\mathrm{B}$ cells make antibodies that attack bacteria and toxins while the T cells attack body cells themselves when they have been taken over by viruses or have become cancerous. Lymphocytes secrete products (lymphokines) that modulate the functional activities of many other types of cells and are often present at sites of chronic inflammation ${ }^{7}$. A lymphocyte is one of the subtypes of white blood cell in a vertebrate's immune system. Lymphocytes include natural killer cells, T cells, B cells. They are the main type of cell found in lymph, which prompted the name "lymphocyte". It is impossible to distinguish between $\mathrm{T}$ cells and B cells in a peripheral blood smear ${ }^{8}$.

\section{MATERIALS AND METHOD}

The study was conducted for a period of 3 months in a tertiary care hospital in Kannur district of Kerala state. Fifty pregnant women between 3-6 months were considered in this study. Out of this fifty, thirty cases were with gestational diabetes and twenty were without gestational diabetes. Pregnant women with diabetes were included in the study and women suffering from hematological disorders, infectious or inflammatory disorders and severe renal or liver disease were exempted from the study.

Patient venous blood samples were drawn in EDTA bottles and mixed gently. Total leukocyte counts and differential leukocyte counts were measured manually. Neutrophil lymphocyte ratio was calculated by dividing absolute neutrophil count to absolute lymphocyte count.

\section{Manual method}

\section{Total leucocyte count}

The blood specimen is diluted 1:20 with diluting fluid and cells are counted under low power of the microscope by using the counting chamber. The numbers of cells in undiluted blood are reported per mm of blood. The glacial acetic acid in the diluting fluid lyses the red cells while gentian violet stains the nuclei of leucocyte ${ }^{9,10 .}$

$$
\begin{aligned}
\text { Total number of WBC's present } / \mathrm{mm} \text { of blood } & =\frac{\text { number of cells counted }}{\text { area } * \text { depth }} \times \text { dilution factor } \\
& =\frac{N}{4 \times 1 / 10} \times 20 \\
& =\mathrm{NX} 50
\end{aligned}
$$

Normal value: $4000-11000$ cells $/ \mathrm{mm}^{3}$ 


\section{Differential leucocyte count}

The Romanowsky staining solution contains methylene blue and eosin or azure. In an appropriate $\mathrm{PH}$ acidic structure take up basic dye and the basic structure stain with acidic dyes. Methylene blue is the basic dye and has affinity for acidic component of cell. These acidic and basic dyes induce multiple colours when applied to cells. Methanol act as fixative and solvent ${ }^{9}$, 10 .

\section{Absolute neutrophil count (ANC)}

Absolute neutrophil count is a measure of the number of neutrophil granulocytes present in the blood. Neutrophils a type of white blood cell that fights against infection. The ANC is calculated from measurements of the total number of white blood cell [WBC], usually based on the combined percentage of mature neutrophils [sometimes called segmented cells] and bands, which are immature neutrophils ${ }^{9,10}$.

$$
\text { Absolute Neutrophil Count (ANC) }=\frac{\% \text { OF NEUTROPHILS } X \text { WBC COUNT }}{100}
$$

Normal range: $1500-8000$ cells $/ \mathrm{mm}^{3}$, Percentage of neutrophils:25-70\%

\section{Absolute lymphocyte count (ALC)}

It is expressed as percentage of lymphocyte to the total number of white blood cells counted ${ }^{9,10 .}$

$$
\text { Absolute Lymphocyte Count }(\mathrm{ALC})=\frac{\% \text { Lymhocytes } X \text { WBC count }}{100}
$$

Normal range: $1300-3500$ cells $/ \mathrm{mm}^{3}$

\section{Neutrophil lymphocyte ratio (NLR)}

Neutrophil to lymphocyte ratio is used as a marker of subclinical inflammation. It is calculated by dividing the number of neutrophils by number of lymphocytes, usually from peripheral blood sample ${ }^{9,10}$.

Neutrophil Lymphocyte Ratio (NLR) $=\frac{\text { Absoulte neutrophil count }}{\text { absoulte lymhocyte count }}$

Normal range: Less than 2

\section{RESULTS AND DISCUSSION}

50 samples were evaluated during the three months period of study. Among these 30 cases were considered to as group 1, which was women with gestational diabetes and 20 were control and considered as group 2 which was women without gestational diabetes. Neutrophil lymphocyte ratio between group 1 and group 2 individuals were calculated and found out that there was an increased neutrophil lymphocyte ratio among the women with GDM. 
Table 1: Neutrophil lymphocyte ratio of the study population (NLR)

\begin{tabular}{lll}
\hline Parameter & $\begin{array}{l}\text { Women with gestational } \\
\text { Diabetes (Group -1) } \mathbf{N}=\mathbf{3 0}\end{array}$ & $\begin{array}{l}\text { Women without gestational } \\
\text { Diabetes (Group - 2) } \mathbf{N = 2 0}\end{array}$ \\
\hline NLR & 3.81 & 1.59 \\
\hline
\end{tabular}

Table 2: Total leucocyte count (TLC) comparison with the control

\begin{tabular}{|c|c|c|}
\hline Parameter & $\begin{array}{l}\text { Women with gestational } \\
\text { Diabetes (Group -1) N=30 }\end{array}$ & $\begin{array}{l}\text { Women without gestational } \\
\text { Diabetes (Group }-2) \mathrm{N}=20\end{array}$ \\
\hline TLC & $\begin{array}{l}\text { Mean of } 30 \text { sample } \\
13966.6 \text { cellsmm }\end{array}$ & $\begin{array}{l}\text { Mean of } 20 \text { sample } \\
9560 \text { cells } / \mathrm{mm}^{3}\end{array}$ \\
\hline
\end{tabular}

Table 3: Absolute neutrophil count (ANC) and absolute lymphocyte count (ALC) of the study population

\begin{tabular}{lll}
\hline Parameter & $\begin{array}{l}\text { Women with gestational } \\
\text { Diabetes (Group -1) } \mathbf{N = 3 0}\end{array}$ & $\begin{array}{l}\text { Women without gestational } \\
\text { Diabetes (Group - 2) } \mathbf{N = 2 0}\end{array}$ \\
\hline ANC & 10821 & 5795 \\
ALC & 2892 & 2825 \\
\hline
\end{tabular}

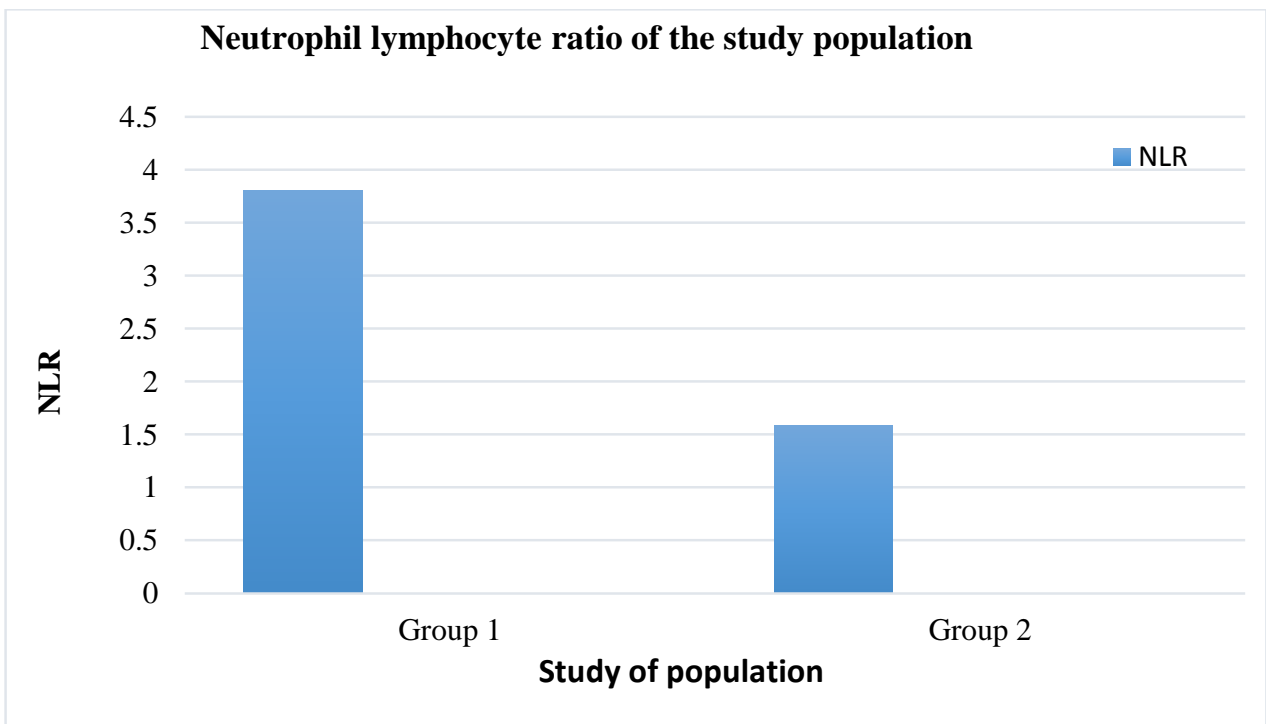

Figure 1: Neutrophil lymphocyte ratio of the study population (NLR) 


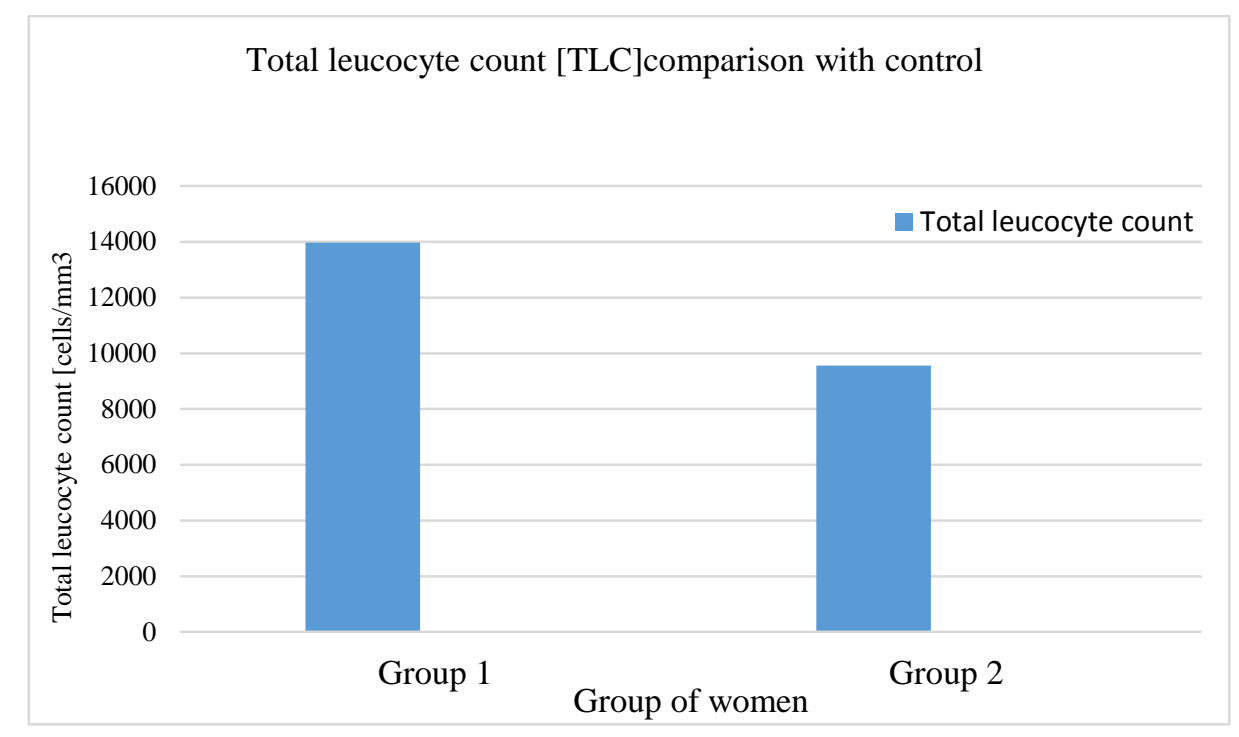

Figure 2: Total leucocyte count (TLC) comparison with the control

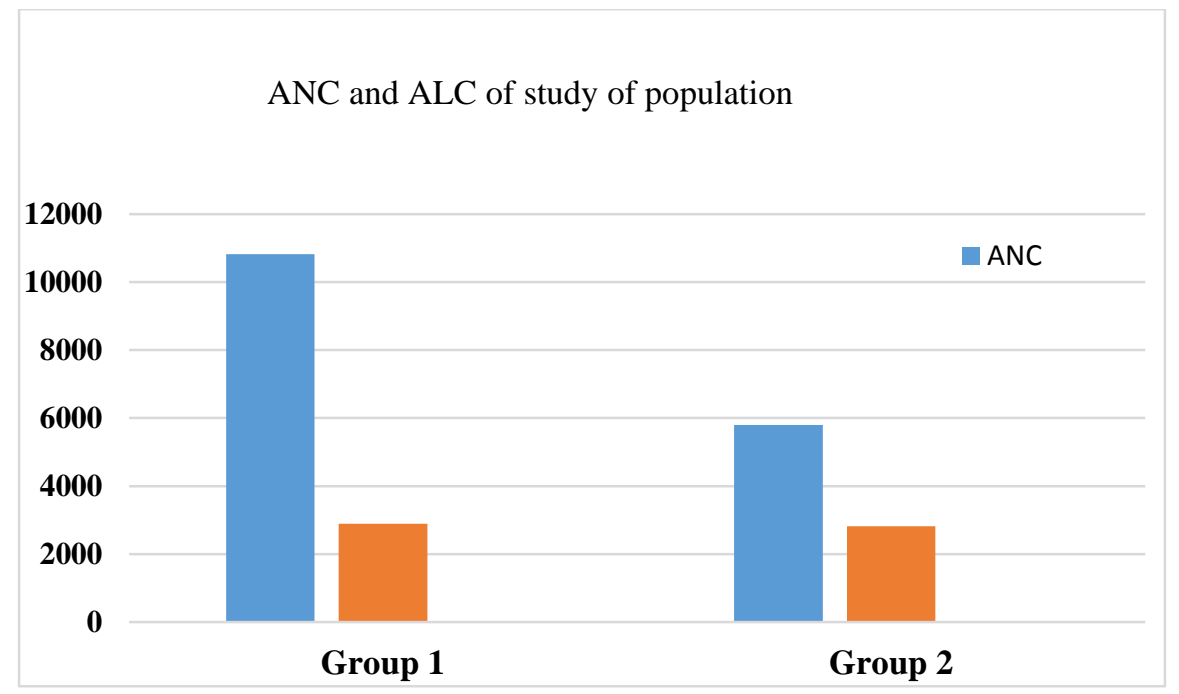

Figure 3: Absolute neutrophil count (ANC) and absolute lymphocyte count (ALC) of the study population

Neutrophil lymphocyte ratio is the sign of balance between neutrophil and lymphocyte in body and an indicator of systemic inflammation. Neutrophil lymphocyte ratio is a predictor of gestational diabetes mellitus in pregnant women. An elevated neutrophil lymphocyte level is a powerful and independent predictor of gestational diabetes mellitus. The results of the study suggested that inflammation plays a central role in the pathogenesis of gestational diabetes mellitus. Thus In this study, a relationship between neutrophil lymphocyte ratio and developing gestational diabetes among women can be clearly observed. Neutrophil lymphocyte ratio has been used to predict diabetes mellitus complications, and it has been shown that an increase in neutrophil lymphocyte ratio is a predictive factor for hearing $\operatorname{loss}^{11}$ and the development of diabetic retinopathy ${ }^{12}$, early diabetic nephropathy ${ }^{13}$, and coronary artery disease ${ }^{14}$ in patients 
with diabetes mellitus. Earlier studies have shown that leukocyte count is associated with gestational diabetes mellitus and type II diabetes. In a prospective study of 2,753 pregnancies, Wolf et al determined that compared with the normoglycemic pregnant women, the first trimester leukocyte count was significantly higher in the patients who developed gestational diabetes mellitus ${ }^{15}$. A high leukocyte count is a marker of inflammation, and it is thought that cytokine-induced insulin resistance is a central mechanism that underlies the relationship between inflammation and gestational diabetes mellitus and diabetes.

\section{REFERENCES}

1. Managing Gestational Diabetes - A PATIENT 'S GUIDE TO A HEALTHY. U.S. Department of Health and Human Services. National institutes of Health. Eunice Kennedy Shiver National Institute of Child Health and Human Development.

2. American Diabetes Association: Position statement—gestational diabetes. Diabetes Care 9:430-31,1986

3. Seshiah V, Balaji V, Balaji MS. Scope for prevention of diabetes-Scope for prevention of diabetes--'focus intrauterine milieu interieur'.J Assoc Physicians India. 2008; 56:10913.

4. Gestational Diabetes Mellitus. American diabetes association. diabetes care, volume 26, supplement.2003;1:103-5105.

5. Rorvig S, Ostergaard O, Heegaard NHH,Borregaard N. Proteomeprofiling of human neutrophil granule subsets, secretory vesicles, and cell membrane :correlation with transcriptome profiling of neutrophil precursors. Journal of Leukocyte Biology.2013; 94:711-721.

6. Niemiec MJ, De Samber B, Garrevoet J, Vergucht E, Vekemans B, De Rycke R, Björn E, Sandblad L, Wellenreuther G, Falkenberg G, Cloetens P, Vincze L, Urban CF (2015). "Trace element landscape of resting and activated human neutrophils on sub-micrometer level". Metallomics. 7 (6): 996-1010.

7. B Cell". Merriam-Webster Dictionary. Encyclopaedia Britannica. Retrieved 28 October 2011.

8. Janeway, Charles; Travers, Paul; Walport, Mark; Shlomchik, Mark (2001). Immunobiology (5th ed.). New York and London: Garland Science. ISBN 08153-4101-6.. 
9. John V Dacie and Lewis SM. Practical Haematology, 1994.edition 8, ELBS with Churchill Livingstone, 75-77.

10. Praful B Godkar and Darshan P Godkar. Text book of medical laboratory technology. Clinical laboratory science and molecular diagnosis. 2014; 3rd edition, Volume 2, Bhalani publishing house, Mumbai, 1108-1115.

11. Ulu S, Bucak A, Ulu MS, et al. Neutrophil-lymphocyte ratio as a new predictive and prognostic factor at the hearing loss of diabetic patients. Eur Arch Otorhinolaryngol. 2014;271(10):2681-2686.

12. Ulu SM, Dogan M, Ahsen A, et al. Neutrophil-to-lymphocyte ratio as a quick and reliable predictive marker to diagnose the severity of diabetic retinopathy. Diabetes Technol Ther. 2013; 15(11):942-947.

13. Huang W, Huang J, Liu Q, et al. Neutrophil-lymphocyte ratio is a reliable predictive marker for early-stage diabetic nephropathy. Clin Endocrinol. 2015; 82(2):229-233.

14. Verdoia M, Schaffer A, Barbieri L, et al. Impact of diabetes on neutrophil-to-lymphocyte ratio and its relationship to coronary artery disease. Diabetes Metab. 2015;41(4):304-311

15. Wolf M, Sauk J, Shah A, et al. Inflammation and glucose intolerance: a prospective study of gestational diabetes mellitus. Diabetes Care. 2004; 27(1):21-27. 